\title{
Nasal Angiofibroma; Ten Years' Experience of Odd Criteria
}

\author{
Original \\ Article \\ Abdelrahman Y. Ali, Hussam Elbosraty and Sameh M Zamzam \\ Department of Otorhinolaryngology, Faculty of Medicine, Cairo University, Cairo, Egypt
}

\begin{abstract}
Introduction: Nasopharyngeal angiofibroma has usual characters regarding its origin, histopathology, vascular feeding and clinical presentation. In this study we have presented some cases of nasopharyngeal angiofibroma with unusual characters.

Methods: A case series study that was conducted on patients with angiofibroma presented to otolaryngology department of Cairo University, between 2010 and 2020. Searching for unusual presentation.

Results: Thirteen male patients with mean age 12.5 years had shown unusual character. Seven cases showed unusual vascular feeding pattern and six cases showed unusual character of anatomical location and extension (3 cases in whom the tumor is entirely medially located to sphenopalatine foramen and another 3 cases in whom the tumor is entirely laterally located to sphenopalatine foramen)

Conclusion: Every day and other rhinologists all over the world report cases of nasopharyngeal angiofibroma. But some uncommon cases do not fulfill the typical epidemiological, pathological and clinical criteria and that is what was presented in this study. This study had highlighted 13 cases of angiofibroma with atypical characters regarding vascular feeding and locoregoinal extension.
\end{abstract}

Key Words: Angiofibroma, juvenile, nasopharynx, sphenopalatine.

Received: 14 January 2021, Accepted: 31 January 2021

Corresponding Author: Sameh M. Zamzam, Department of Otorhinolaryngology, Faculty of Medicine, Cairo University, Cairo, Egypt, Tel.: +20 1099757741, E-mail: samehzamzam@hotmail.com

ISSN: 2090-0740, 2021

\section{INTRODUCTION}

Typically Juvenile nasopharyngeal angiofibroma (JNA) is a vascular benign tumor that is usually affect nasopharynx of male children and adolescents, it represents $0.05 \%$ to $0.5 \%$ of head and neck tumors ${ }^{[1]}$. It frequently originates from sphenopalatine foramen and extends to both nasal cavity and pterygopalatine fossa, histologically composed of vascular spaces and fibrous stroma, gets its vascular feeding from branches of external carotid artery, usually pseudocapsulated ${ }^{[2-3]}$. The typical symptoms of angiofibroma are aural fullness, nasal obstruction and epistaxis $^{[4]}$.

However some cases do not fulfill the previous typical criteria regarding feeding vessels and location and that is what we represented in this study.

\section{PATIENTS AND METHODS}

This study is a case series study was conducted on thirteen male patients aged from 7 to 18 years old presented with juvenile angiofibroma with unusual criteria to otolaryngology department at Cairo University hospitals, between 2010 and 2020. All patients were subjected to full medical history taking, endoscopic nasal examination \& CT scan and MRI on nose and paranasal sinuses with coronal $\&$ axial and sagittal views. Also all patients were asked to sign a written informed operative consent. All Cases subjected to preoperative endocatheter embolisation of the feeding vessels and managed surgically by endoscopic endonasal approach. In this study we had excluded the cases of classic presentation of unilateral nasal mass with classic extension to pterygopalatine fossa $+/$ - infratemporal fossa (dumbbell shaped) angiofibroma.

\section{RESULTS}

We have classified these 13 cases into three groups according to the unusual criteria. Group of bilateral vascular feeders (7 patients) (Figures 2-8) and group of only medial location of the tumor to sphenopalatine foramen (3 patients) (Figures 9-11) and group of only lateral location of the tumor to sphenopalatine foramen (3 patients) (Figures 12-14).

Regarding to the group of bilateral feeders (7 cases), preoperative radiological imaging has put angiofibroma as a differential diagnosis. Preoperative biopsy was taken from 5 patients; only one patient was radiologically confirmed.

All the 7 cases were subjected to preoperative angiography and vascular embolisation, the feeding pattern was from both internal and external carotid arteries, figure 1 , vascular embolisation controlled average $60-80 \%$ of feeding in the 7 cases.

Average duration of surgery was 185 minutes. The blood loss varied from $750 \mathrm{ml}$ to $2300 \mathrm{ml}, 2-4$ units of blood transfusion was needed for each patient. 

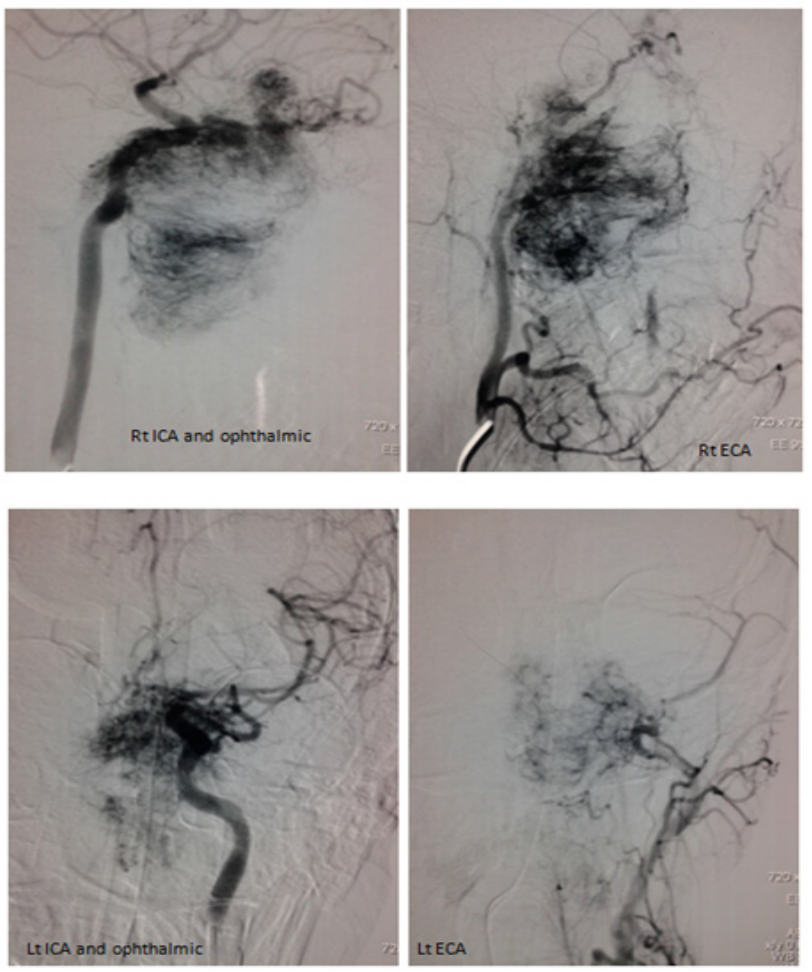

Fig. 1: labeled pictures show angiography of both internal and external carotids on both sides feeding an angiofibroma (a case of bilateral feeders)

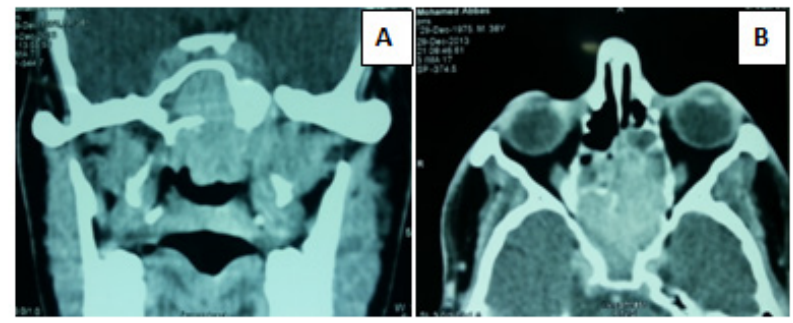

Fig. 2: A \& B: preoperative coronal and axial CT scan in order of case number 1 (case of bilateral feeders)

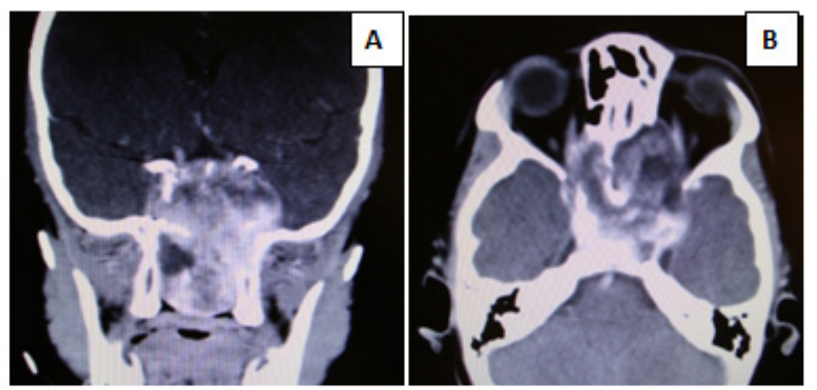

Fig. 3: A \& B: preoperative coronal \& axial CT scan in order of case number 2 (case of bilateral feeders)

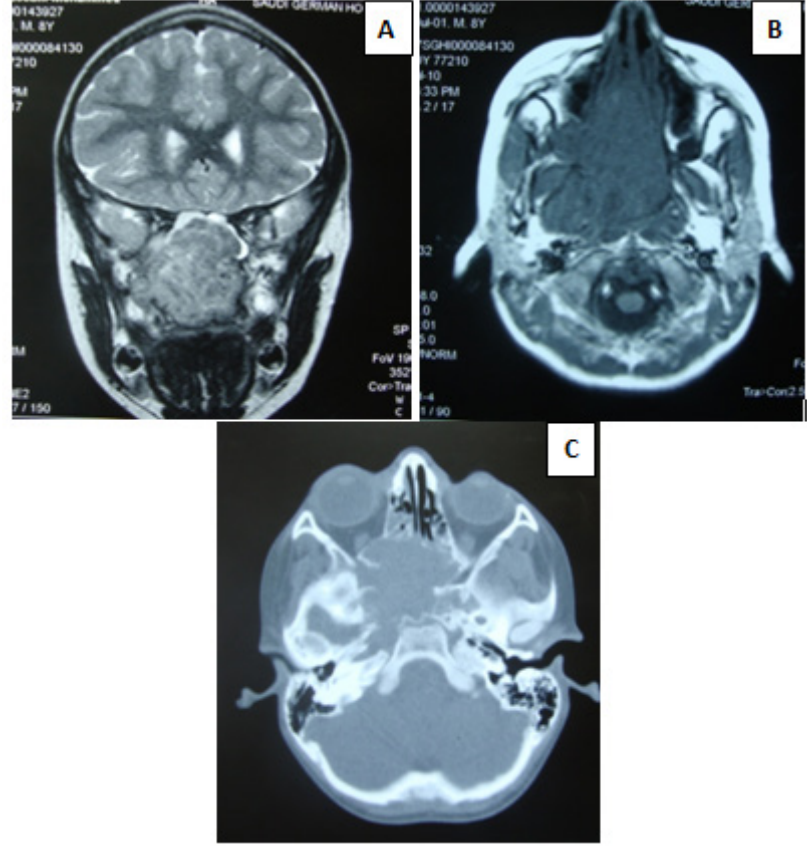

Fig. 4: A \& B: preoperative coronal and axial MRI in order. C: preoperative axial CT scan of case number 3 (case of bilateral feeders)

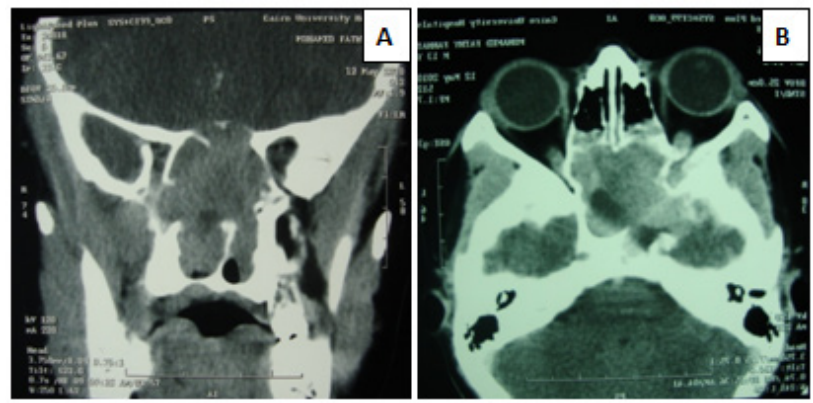

Fig. 5: A \& B: preoperative coronal and axial CT scan in order of case number 4 (case of bilateral feeders)

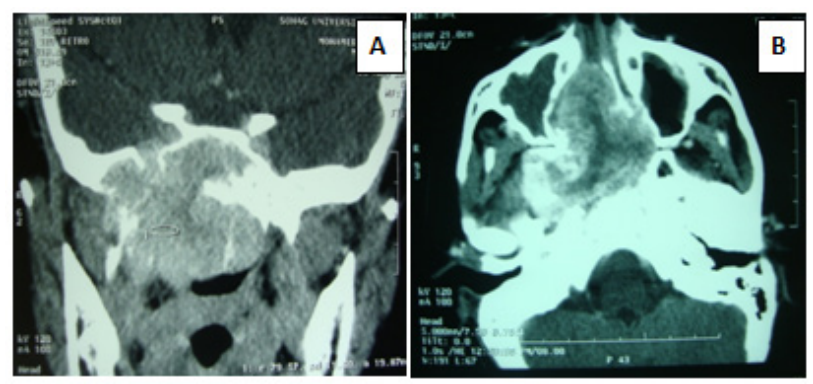

Fig. 6: A \& B: preoperative coronal and axial CT scan in order of case number 5 (case of bilateral feeders) 


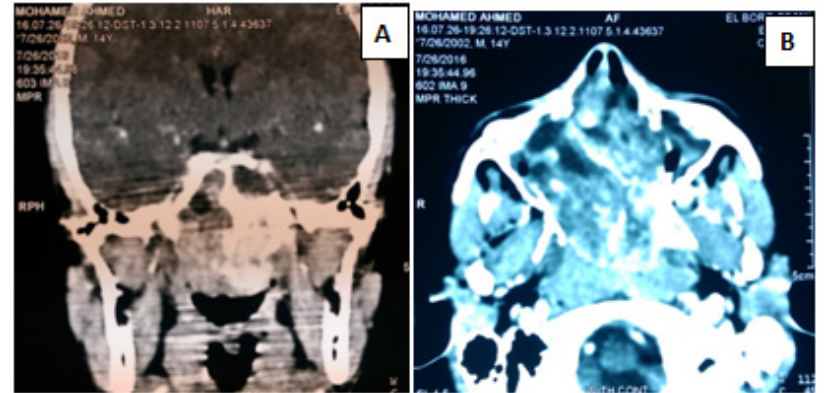

Fig. 7: A \& B: preoperative coronal and axial CT scan in order of case number 6 (case of bilateral feeders)

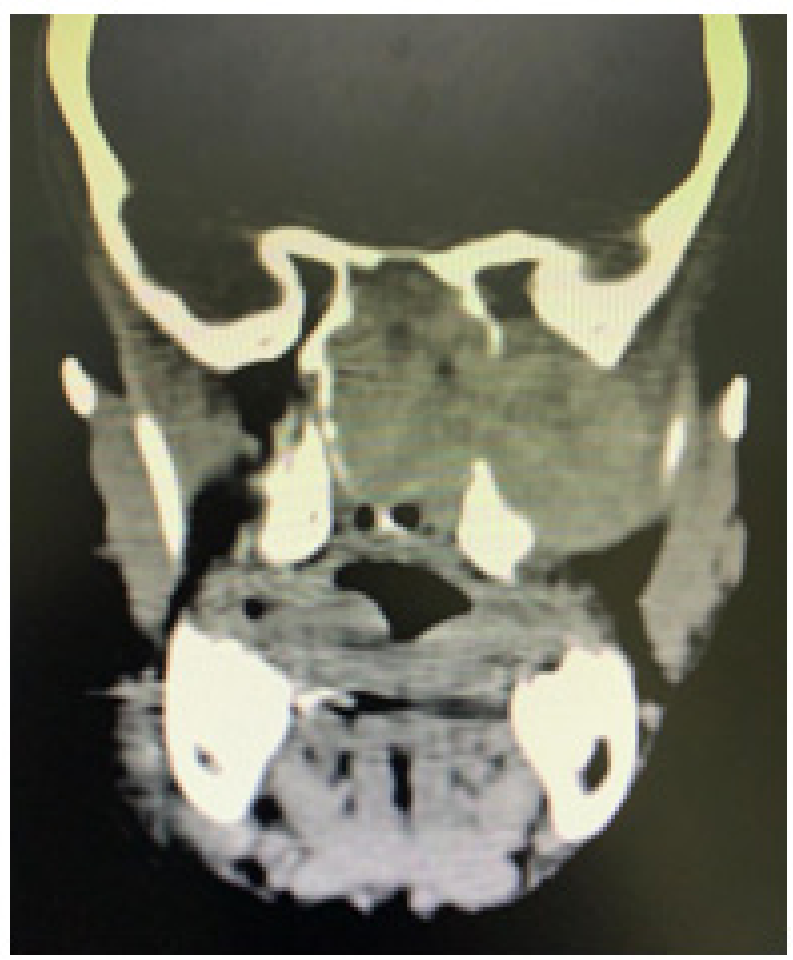

Fig. 8: preoperative coronal CT scan of case number 7 (case of bilateral feeders)
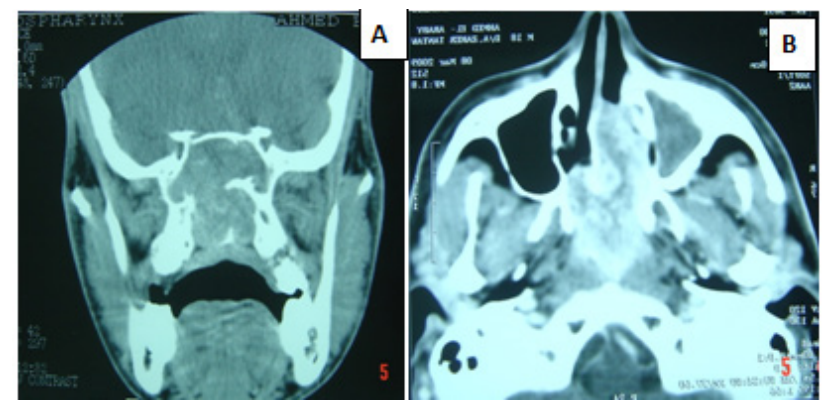

Fig. 9: A \& B: preoperative coronal and axial CT scan in order of case number 8 (case of pure medial location)
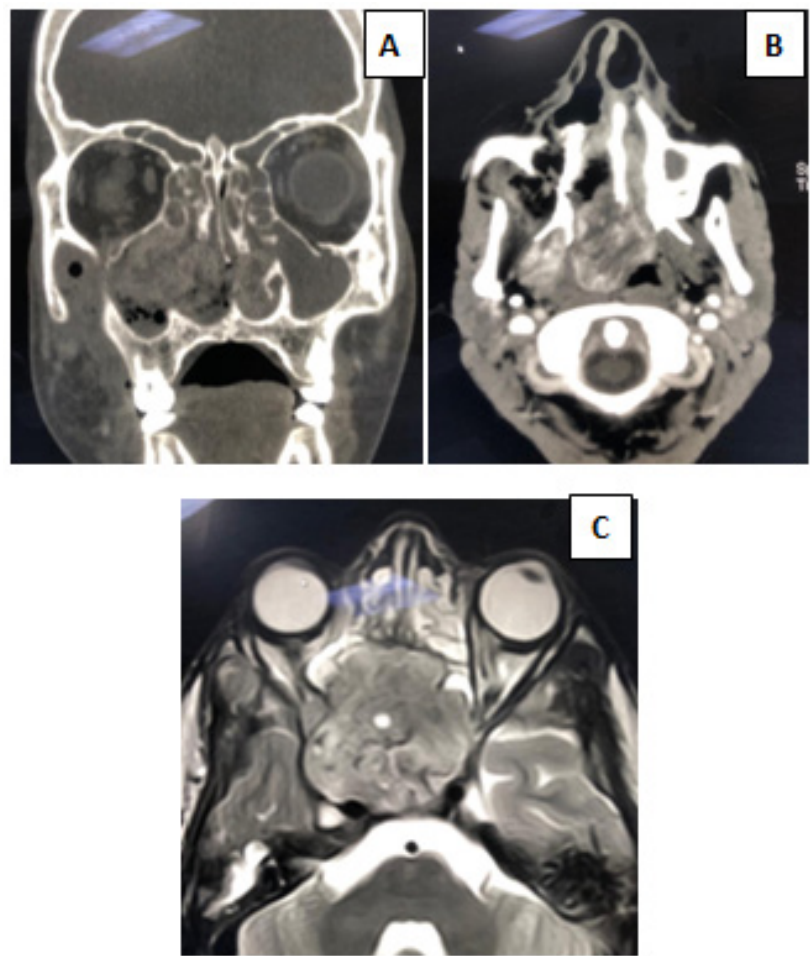

Fig. 10: A \& B: preoperative coronal and axial CT scan in order. C: preoperative axial MRI of case number 9 (case of pure medial location)

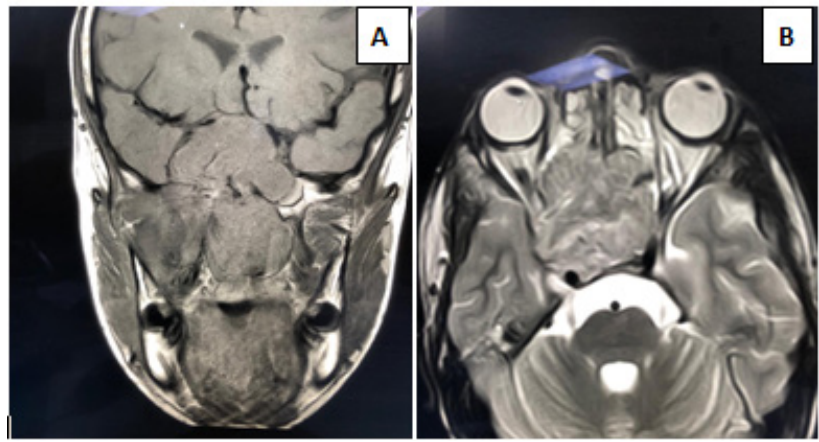

Fig. 11: A \& B: preoperative coronal and axial MRI in order of case number 10 (case of pure medial location)

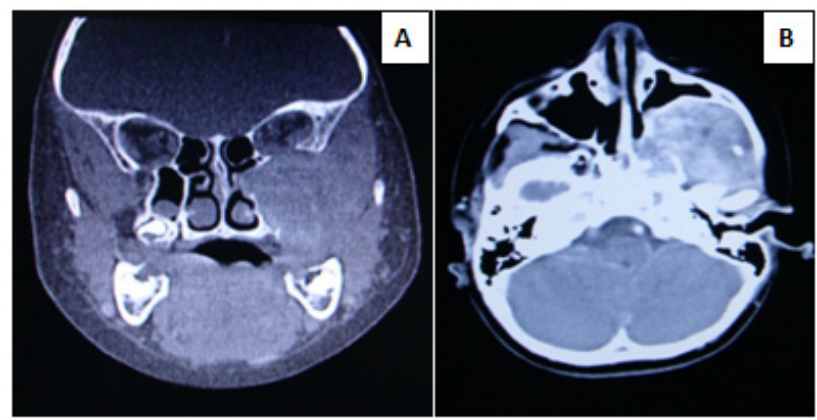

Fig. 12: A \& B: preoperative coronal and axial CT scan in order of case number 11 (case of pure lateral location) 

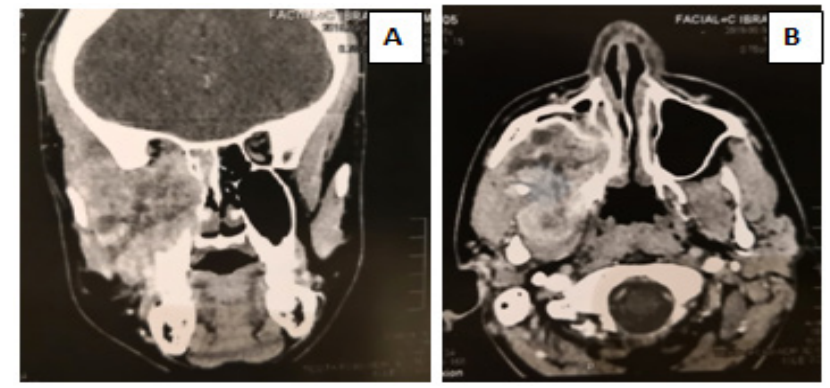

Fig. 13: A \& B: preoperative coronal and axial CT scan in order of case number 12 (case of pure lateral location)

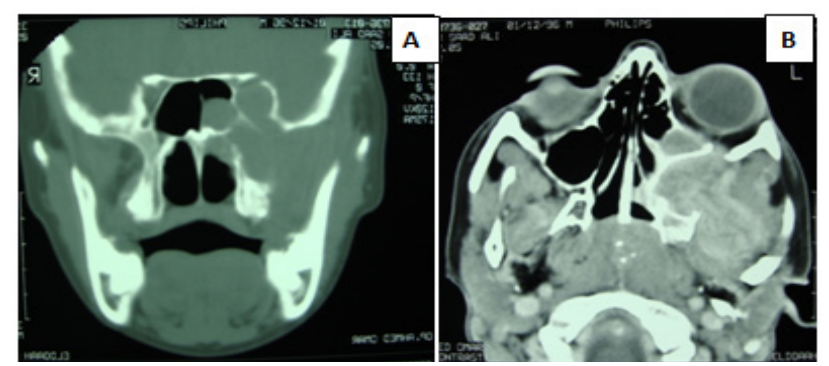

Fig. 14: A \& B: preoperative coronal and axial CT scan in order of case number 13 (case of pure Lateral location)
Two cases were subjected to incomplete removal of the tumor leaving a residual encroaching the internal carotid artery. One of both has received radiotherapy with no recurrence and no evidence of any malignancies of the head \& neck along the follow up period. The other case was re-operated endoscopically a year next and the patient died from disseminated intravascular coagulopathy.

On the other hand the group of only medial presentation ( 3 cases), preoperative CT was suggestive for angiofibroma, no biopsies were taken preoperatively, preoperative embolisation showed ipsilateral supply from external carotid artery branches. Average duration of surgery was 95 minutes with average blood loss $300 \mathrm{ml}$ controlled by 0-1 units of blood transfusion.

The $3^{\text {rd }}$ group of only lateral location ( 3 cases), one case has needed a preoperative biopsy, angiography showed ipsilateral supply from external carotid artery branches. Average duration of surgery was 130 minutes with average blood loss $500 \mathrm{ml}$ controlled by 1-2 units of blood transfusion (Table 1).

Table 1: Details of this study cases

\begin{tabular}{|c|c|c|c|c|c|c|c|}
\hline Case number & Group & $\begin{array}{c}\text { Preoperative } \\
\text { biopsy }\end{array}$ & Feeding vessels & $\begin{array}{c}\text { Duration of } \\
\text { surgery }\end{array}$ & $\begin{array}{c}\text { Blood } \\
\text { Transfusion }\end{array}$ & Consequences & $\begin{array}{c}\text { Follow up } \\
\text { duration }\end{array}$ \\
\hline 1 & & + & & 180 minutes & 3 units & - & 9 years \\
\hline 2 & & - & & 200 minutes & 4 units & $\begin{array}{c}\text { Leaving a } \\
\text { residual \& } \\
\text { postoperative } \\
\text { radiotherapy }\end{array}$ & 10 years \\
\hline 3 & Bilateral feeders & - & $\begin{array}{l}\text { Both ICA } \\
\& \text { ECA on } \\
\text { both sides }\end{array}$ & 200 minutes & 4 units & $\begin{array}{l}\text { Leaving a } \\
\text { residual \& } \\
\text { re-operated } \\
\text { and died }\end{array}$ & 9 years \\
\hline 4 & & + & & 180 minutes & 4 units & - & 6 years \\
\hline 5 & & + & & 160 minutes & 2 units & - & 2 years \\
\hline 6 & & + & & 190 minutes & 2 units & - & 7 years \\
\hline 7 & & + & & 180 minutes & 4 units & - & 4 years \\
\hline 8 & & - & & 90 minutes & - & - & 2 years \\
\hline 9 & Medially located & - & & 100 minutes & - & - & 3 years \\
\hline 10 & & - & Ipsilateral & 100 minutes & 1 unit & - & 6 years \\
\hline 11 & & + & ECA branches & 140 minutes & 1 unit & - & 8 years \\
\hline 12 & Laterally located & - & & 120 minutes & 2 units & - & 1 year \\
\hline 13 & & - & & 140 minutes & 1 unit & - & 5 years \\
\hline
\end{tabular}

ICA: Internal Carotid Artery

ECA: External Carotid Artery

\section{DISCUSSION}

Juvenile nasopharyngeal angiofibroma is typically receives blood supply via the ascending pharyngeal artery (APA) or via another branch from external carotid artery ${ }^{[5]}$.

In this study we have represented 7 cases of JNA with bilateral vascular feeders that were detected by preoperative embolisation, all cases were treated endoscopically with no significant complications. Wu et al had published a case report of 4 cases of JNA with bilateral feeding blood vessels; the preoperative angiography showed only right-sided vascular feeding. However, significant intraopeartive bleeding was noticed, and an intraoperative angiography showed significant new vascularization from the left ascending pharyngeal artery (APA), the surgery was completed successfully after converting to an open 
approach. The other 3 cases were diagnosed as bilateral feeders preoperatively and managed endoscopically ${ }^{[6]}$.

In this study we had classified the atypically of JNA presentations according to the unilaterality or bilaterality of vascular feeding ( 7 cases) and according to the location and extension either medial or lateral to sphenopalatine foramen (6 cases). A study by Toplu et al had reported a case of atypical location at the middle turbinate ${ }^{[7]}$. Another study by Celik et al had reported 4 cases with atypical presentation, one case with atypical symptom which is bulge in cheek and 3 cases with a typical location in palatine tonsils ( one case) and inferior turbinate $(2 \text { cases })^{[8]}$. Another 2 studies by Nomura et al and Taggarshe et al had reported an atypical location at the inferior turbinate ${ }^{[9-10]}$. And a study by Mehta et al had reported a case was presented by coughing of fresh blood drops with negative history of tuberculosis or other pulmonary disease ${ }^{[11]}$.

A study by Ferraz et al had reported a case of JNA at the inferior turbinate of 8 years old gir ${ }^{[12]}$ another two studies had detected angiofibroma in a female patients ${ }^{[13-14]}$. On the other hand all cases in the present study were males and no female cases has been reported (Table 2).

Finally, this study has some drawbacks, the few number of cases as the study has been carried out in one institute and relatively looking for odd cases and this was reflected in the inability to conduct a statistical analysis. Future studies including more number of patients and in multiple institutes with multiple surgeons.

Table 2: Comparison between different studies

\begin{tabular}{|c|c|c|}
\hline Study & Criteria of atypicality & Number of cases \\
\hline The present study & $\begin{array}{ll}\text { - } & \text { Bilateral vascularity } \\
\text { - } & \text { Only medial location } \\
& \text { Only lateral location }\end{array}$ & $\begin{array}{ll} & 7 \\
\cdot & 3 \\
\cdot & 3\end{array}$ \\
\hline Wu et al & Bilateral vascularity & 4 \\
\hline Toplu et al & Located at middle turbinate & 1 \\
\hline Celik et al & $\begin{array}{ll}\text { - } & \text { Located at palatine tonsil } \\
\text { - } & \text { Located at inferior turbinate } \\
\text { - } & \text { Atypical clinical symptoms }\end{array}$ & $\begin{array}{ll}\cdot & 1 \\
\cdot & 2 \\
\cdot & 1\end{array}$ \\
\hline Nomura et al & Located at inferior turbinate & 1 \\
\hline Taggarshe et al & Located at inferior turbinate & 1 \\
\hline Mehta et al & Atypical clinical symptoms & 1 \\
\hline Ferraz et al & Female sex & 1 \\
\hline Al-Ahmari and Assiri & Female sex & 1 \\
\hline Ralli et al & Female sex & 1 \\
\hline
\end{tabular}

\section{CONCLUSION}

Every day and other rhinologists all over the world report cases of nasopharyngeal angiofibroma. But some uncommon cases do not fulfill the typical epidemiological, pathological and clinical criteria and that is what was presented in this study. This study had highlighted 13 cases of angiofibroma with atypical characters regarding vascular feeding and locoregoinal extension.

\section{CONFLICT OF INTERESTS}

There are no conflicts of Interest.

\section{REFERENCES}

1. Makhasana JA, Kulkarni MA, Vaze S, Shroff AS. Juvenile nasopharyngeal angiofibroma. J Oral Maxillofac Pathol. 2016; 20(2):330.

2. Overdevest JB, Amans MR, Zaki P, Pletcher SD, ElSayed IH. Patterns of vascularization and surgical morbidity in juvenile nasopharyngeal angiofibroma: A case series, systematic review, and meta-analysis. Head Neck. 2018; 40(2):428-43.
3. Szymańska A, Szymański M, Czekajska-Chehab E, Szczerbo-Trojanowska M. Invasive growth patterns of juvenile nasopharyngeal angiofibroma: radiological imaging and clinical implications. Acta Radiol. 2014; 55(6):725-31.

4. McKnight CD, Parmar HA, Watcharotone K, Mukherji SK. Reassessing the Anatomic Origin of the Juvenile Nasopharyngeal Angiofibroma. J Comput Assist Tomogr. 2017 41(4):559-64.

5. Schick B, Kahle G. Radiologic findings in angiofibroma. Acta Radiologica 2000; 41:585-93.

6. Wu AW, Mowry SE, Vinuela F, Abemayor E and Wang MB. Bilateral Vascular Supply in Juvenile Nasopharyngeal Angiofibromas Laryngoscope. 2011; 121: 639-43

7. Toplu Y, Can S, Sanl M, Sahin N and Kizilay A. Middle turbinate angiofibroma: an unusual location for juvenile angiofibroma. Brazelian journal of otorhinolaryngology 2018; 122-5 
8. Celik B, Erisen L, Saraydaroglu $\mathrm{O}$ and Coskun H. Atypical angiofibromas: a report of four cases. international journal of pediatric otorhinolaryngology. 2005; 69: 415-21

9. Nomura K, Shimomura A, Awataguchi T, Murakami K and Kobayashi K. Acase of angiofibroma originating from the inferior nasal turbinate. Auris Nasus Larynx. $2006 ; 191-3$

10. Taggarshe $\mathrm{D}$, Dugar Q. Inferior turbinate angiofibroma: an atypical preservation. Rhinology. 2004; 42: 45-7

11. Mehta AK, Bindra MS and Ravikumar. Nasal angiofibroma : An Unusual Presentation. Med J Armed Forces India. 2001; 57(1): 59-60.
12. Ferraz MA, Pinna FR and Voegels RL. Extranasopharyngeal Angiofibroma Originating at an Unusual Site in the Inferior Turbinate. Int Arch Otorhinolaryngol. 2014; 18:403-5.

13. Al-Ahmari MS and Assiri KS. Juvenile nasopharyngeal angiofibroma in a woman: a rare case report the Egyptian journal of hospital medicine. 2018; 72 (5):4572-75

14. Ralli M, Fusconi M, Visconti IC, Martellucci S, Vincentiis $M$ and Greco A. Nasopharyngeal angiofibroma in an elderly female patient: a rare case report Molecular and clinical oncology. 2018; 9 (6) : 702-4 